\title{
New sorption materials based on modification of natural zeolites in metal wastewater treatment processes
}

\author{
Marina Obuzdina ${ }^{1, *}$ and Elena Rush $^{1}$ \\ ${ }^{1}$ Irkutsk State Transport University, Irkutsk, Russian Federation
}

\begin{abstract}
This study considers the problem of wastewater treatment from heavy metal ions and possible ways to solve it, for example, by modifications of natural zeolites from the deposits of Transbaikalia region. We offer a method of modifying the structure of natural zeolite with a sulfur-containing polymer derived from epichlorohydrin waste, the main component of the 1.2,3- trichloropropane. The sulfurcontaining polymer mesh is formed by the use of the dissolution of sulfur at room temperature in the system of mono-ethanolamine-hydrazine hydrate and condensation with 1.2,3-trichlorpropane. The result of applying a sulfur-containing polymer mesh lies not only in the hydrophobization of the zeolite surface, but also in the appearance of sulfur atoms in its composition, which contributes to an increase in the selectivity with respect to heavy metal ions. We demonstrate the possibility of using new sorption materials in deep wastewater treatment processes of galvanic production. As a load for the adsorbent filter, we propose to use a three-layer filtering material with a load of natural zeolite of various modifications. It has been proven that such chemical modification of zeolite allows to obtain sorbents with an increased surface area and transitional pores that have a high sorption activity in relation to heavy metal ions.
\end{abstract}

\section{Introduction}

Currently, when the treatment of industrial wastewater from pollutant components of various chemical nature has become one of the most common technological processes, the issues of its improvement and optimization seem especially relevant. Insufficiently purified wastewater of enterprises, engineering, metallurgy, and galvanic production make up the bulk of pollution of the surface water objects of the Irkutsk region in the form of toxic compounds of heavy metals [1].

The problem of pollution of water bodies with wastewater determines the feasibility of analyzing the possibilities of improving technological methods and techniques for treating wastewater from heavy metal ions and their compounds.

In the practice of cleaning metal-containing wastewater, withdrawn from various processes (e.g., the processes of applying galvanic coatings) reagent, electrochemical, galvanocoagulation, ion-exchange, adsorption methods are applied. Adsorption methods of cleaning industrial wastewater from pollution of various chemical natures based on the use of natural, modified, synthetic sorbents are becoming more widespread, both in preliminary and final stages of the cleaning chain process, as well as self-sustaining methods. The efficiency of sorption extraction of heavy metals from solutions can reach $80-95 \%$, and the quality of the cleaning process is based on the chemical nature of adsorbent, the area of the adsorption surface and its availability, on the chemical structure of the substance and its condition in the solution [2-4].

Analysis of published works in the field of theoretical and applied research, development and improvement of wastewater treatment technologies from heavy metal ions showed that the process of ion exchange adsorption was sufficiently justified [5-7], while the theory of adsorption by a complex coordination mechanism, is practically not developed. It has been proved that natural zeolites have an adsorption capacity with respect to heavy metal ions, realized mainly due to the ion exchange mechanism, but their adsorption activity is not high enough. Therefore, a promising area of research is the creation of new sorption materials with high selective sorption activity in relation to heavy metals, based on the modification of natural zeolites.

As modifiers of natural zeolite (field of East Transbaikalia) [8] we used high-silicon compounds hexamethyldisilane $\left[\left(\mathrm{CH}_{3}\right)_{3} \mathrm{Si}_{-}\right]_{2} \mathrm{NH}$ (HMDS) and tetraethoxysilane $\left(\mathrm{C}_{2} \mathrm{H}_{5} \mathrm{O}\right)_{4} \mathrm{Si}$ (TEOS), that were facilitating hydrophobization of the surface.

Experimental studies to determine the sorption ability of natural zeolites (of clinoptylolite type), modified with tetraethoxysilane and hexamethyldisilane, were conducted in static conditions as follows: $1 \mathrm{~g}$ of Tetraethoxysilane was dissolved in $100 \mathrm{ml}$ of toluene. The resulting solution was then mixed with $100 \mathrm{~g}$ of

\footnotetext{
*Corresponding author: obuzdina_mv@mail.ru
} 
natural zeolite for

30 minutes. The remains of the toluene were drained, and the modified zeolite was dried for 3 days in the open air and then in a muffle furnace for 6 hours at $110^{\circ} \mathrm{C}$. The modification of hexamethyldisilane was done in a similar way.

The increase in the sorption capacity of modified zeolite, compared to the natural mineral, is due to its greater porousness for heavy metal ions and additional complex coordination adsorption [9]. Adsorbents have been practically tested to extract the $\mathrm{Ni}^{2+}$ and $\mathrm{Zn}^{2+}$ ions from the industrial wastewater of the railway transport companies. We have determined that zeolite modified with HMDS has higher selective adsorption activity in relation to heavy metal ions compared to the one modified with TEOS.

Heavy metals that are considered thiol poisons have a high affinity with sulfur atoms and form with sulfur ions resistant water insoluble sulfides, and with sulfur atoms that are present in organic molecules-strong coordination compounds. Effective extractants and adsorbents for the extraction of heavy metal ions from wastewater are created using this principle $[10,11]$. Thus, the modification of zeolite with a sulfur-containing polymer allowed us to create an adsorbent with high adsorption activity with respect to $\mathrm{Ni}^{2+}, \mathrm{Zn}^{2+}, \mathrm{Cu}^{2+}$

The works [12,13] presented the results of research of ways to create sulfur-containing polymers where solid particles act as polycondensation centers. When sulfur was exposed to an alkaline hydrazine solution, polysulfide anions $\left(\mathrm{S}^{2-}\right)$ were obtained. Previously, the anions were adsorbed onto the surface of the ash and slag material or oil coke, which ensured further polycondensation with the participation of solid particles and trichloropropane. However, natural zeolites almost cannot adsorb anions, therefore, coating their surface with a sulfur-containing polymer was not possible using this method. When creating the sorbent - zeolite modified with a sulfur-containing polymer, not an alkaline solution of hydrazine hydrate was used, but a monoethanolamine-hydrazine hydrate system.

\section{Methods}

We propose a method of obtaining solid granular sulfurcontaining sorbents using epichlorhydrine waste for purification of wastewater from heavy metal ions. Epichlorhydrnie is the main raw material in the synthesis of glycerin, epoxy resins, chlorhydrine rubbers and a number of other products. The waste it produces consists of more than 40 different components, many of which have not been identified yet. Known by-products include: 2,2 - dichlorpropane; 1,2- dichlorpropane; 1,3dichlorpropene; 1,2,3-trichlorpropane; dichlorpropanols; chlorethers. The main component is1,2,3-trichlorpropane [14].

New adsorption material obtained by modification of the natural zeolite of clinoptilolite type by dissolving sulfur in the monoethanolamine-hydrazine hydrate system (mole ratio $1: 10$ ) at the mole ratio of $\mathrm{S}$ : monoethanolamine of $6: 1$, which leads to the formation of anions $\mathrm{S}^{2-}$ on the surface of the zeolite. Dissolution of sulfur obeys the following equations:

1) $\mathrm{N}_{2} \mathrm{H}_{4} \cdot \mathrm{H}_{2} \mathrm{O}+4 \mathrm{~S}+4 \mathrm{HOCH}_{2} \mathrm{CH}_{2} \mathrm{NH}_{2} \longrightarrow 2\left(\mathrm{HOCH}_{2} \mathrm{CH}_{2} \mathrm{NH}_{3}\right)_{2} \mathrm{~S}_{2}+\mathrm{N}_{2}+\mathrm{H}_{2} \mathrm{O}$

2) $5 \mathrm{~N}_{2} \mathrm{H}_{4} \cdot \mathrm{H}_{2} \mathrm{O}+4 \mathrm{~S} \longrightarrow 2\left(\mathrm{~N}_{2} \mathrm{H}_{5}\right)_{2} \mathrm{~S}_{2}+\mathrm{N}_{2}+5 \mathrm{H}_{2} \mathrm{O}$

The formed hydrazinium disulfides $\left(\mathrm{N}_{2} \mathrm{H}_{5}\right)_{2} \mathrm{~S}_{2}$ and hydroxyethylammonium $\left(\mathrm{HOCH}_{2} \mathrm{CH}_{2} \mathrm{NH}_{3}\right)_{2} \mathrm{~S}_{2}$ in hydrazine hydrate dissociate into ions, as in a polar solvent:

$$
\begin{aligned}
& \left(\mathrm{HOCH}_{2} \mathrm{CH}_{2} \mathrm{NH}_{3}\right)_{2} \mathrm{~S}_{2} \longleftrightarrow 2 \mathrm{HOCH}_{2} \mathrm{CH}_{2} \mathrm{NH}_{3}^{+}+\mathrm{S}_{2}{ }^{2-} \\
& \left(\mathrm{N}_{2} \mathrm{H}_{5}\right)_{2} \mathrm{~S}_{2} \longleftrightarrow 2 \mathrm{~N}_{2} \mathrm{H}_{5}^{+}+\mathrm{S}_{2}{ }^{2-}
\end{aligned}
$$

The resulting cations can be adsorbed by zeolite, including, entering the frame cavities of the zeolite structure. Anti-ions $S_{2}^{2-}$ near the zeolite surface compensate for the positive charge that is obtained by the adsorption of cations.

With the addition of 1,2,3-trichlorpropane, which is the main waste of the production of an important monomer-epichlorhydrine, there is a polycondensation with the anions S22- :

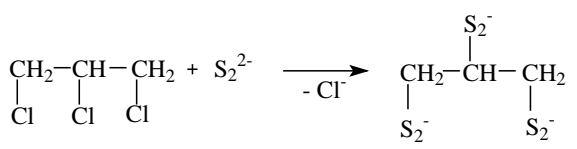

When coating surfaces of zeolite particles with a mesh polymer, the pellets of light yellow color uniform in composition are formed.

The experiment has confirmed that the appropriate amount of zeolite relative to the amount of sulphur is in a ratio of the mass of zeolite: sulfur of $5: 1$. If we reduce the mass of zeolite, the polymer formed in the water solution does not get deposited on the surface of the zeolite. Increased mass of zeolite leads to uneven coating of the surface of zeolite with sulphurous polymer, which leads to the fact that some particles of zeolite practically do not contain sulphur-containing coating. Atomic ratio $\mathrm{S}: \mathrm{Cl}$ of $1: 1$ at the mole ratio of S:trichlorpropane $1: 3$ justifies the amount of trichlorpropane corresponding to the stegiometric ratio at which anion $\mathrm{S}^{2-}$ can replace two $\mathrm{Cl}$ atoms in trichlorpropane.

As an example of obtaining a sulfur-modified zeolite polymer, we can consider the following method: Powdered sulfur (mass $4.0 \mathrm{~g}$ or $0.125 \mathrm{~mol}$ ) was introduced into a mixture of hydrazine hydrate (mass $10.5 \mathrm{~g}$ or $0.21 \mathrm{~mol}$ ) and monoethanolamine (mass $1.28 \mathrm{~g}$ or $0.021 \mathrm{~mol}$ ). At a temperature of $60-65{ }^{\circ} \mathrm{C}$, the mixture was thoroughly mixed for $3.5 \mathrm{~h}$, then it was cooled to room temperature and $20 \mathrm{~g}$ of natural zeolite with an average particle size of $5 \mathrm{~mm}$ was sprinkled on it. While stirring, $21 \mathrm{~g}$ of hydrazine hydrate was introduced, and 1,2,3-trichloropropane ( $0.042 \mathrm{~mol}$ or $6.2 \mathrm{~g}$ ) was added dropwise. For the following 3 hours, the reaction mixture was stirred in a shaker at room temperature. The precipitate was filtered, washed with water, then with acetone and dried in vacuum. The obtained precipitate weighing $23.5 \mathrm{~g}$ was divided into two fractions-No. 1 and No. 2. The composition of the organogenic elements in the average sample of sorbents is presented in table 1 . Those elements that are part of the zeolite itself are not presented in the table. 
We should note that this adsorbent does not melt until $350{ }^{\circ} \mathrm{C}$; however, decomposition of the surface polymer is observed above this temperature. The formation of heavy metal complexes on the surface of modified zeolites has been proved by IR spectroscopy and energy dispersive X-ray spectroscopy [15].

The adsorption characteristics of the sorbents obtained in the above example were studied using model solutions of metal salts $\left(\mathrm{NiCl}_{2}, \mathrm{CuCl}_{2}, \mathrm{CdCl}_{2}\right.$,
$\left.\mathrm{Zn}\left(\mathrm{NO}_{3}\right)_{2}, \mathrm{~Pb}\left(\mathrm{NO}_{3}\right)_{2}, \mathrm{Hg}\left(\mathrm{NO}_{3}\right)_{2}\right)$ with a metal ion concentration of $5000 \mathrm{mg} / \mathrm{g}$ with the purpose of establishing the maximum adsorption capacity of the zeolite modified with sulfur polymer. A weighed portion of the sorbent $(0.5 \mathrm{~g})$ was shaken with $50 \mathrm{ml}$ of salt solution on a $\quad$ S-3.02.08.M shaker for 3 hours. The residual concentration of metal ions was determined on a KFK-3-30 MZ photocolorimeter using the dithizone method.

Table 1. The composition of organic elements in the average sample of adsorbents

\begin{tabular}{|c|c|c|c|c|c|}
\hline $\begin{array}{c}\text { Composition } \\
\text { of adsorbent } \\
\%\end{array}$ & $\begin{array}{l}\text { Fraction } \\
\quad \text { No } 1\end{array}$ & $\begin{array}{c}\text { Fraction } \\
\text { No } 2\end{array}$ & Adsorbent feature & $\begin{array}{l}\text { Fraction } \\
\quad \text { No } 1\end{array}$ & $\begin{array}{c}\text { Faction No } \\
2\end{array}$ \\
\hline $\mathrm{C}$ & 11.12 & 9.02 & Particle size, mm & $1-2$ & $2.5-5.0$ \\
\hline $\mathrm{H}$ & 2.12 & 1.71 & Mass, g. & 10.73 & 12.54 \\
\hline $\mathrm{N}$ & 0.94 & 0.84 & \multirow{3}{*}{$\begin{array}{c}\text { Darkens at } \\
\text { temperature, }{ }^{\circ} \mathrm{C}\end{array}$} & \multirow{3}{*}{240} & \multirow{3}{*}{260} \\
\hline $\mathrm{S}$ & 31.07 & 22.19 & & & \\
\hline $\mathrm{Cl}$ & 1.92 & 1.54 & & & \\
\hline
\end{tabular}

The magnitude of sorption A (mg/g) was estimated based on the reduction of the concentration of metal ions in the solution according to the following formula [4]:

$$
A=\frac{V \cdot\left(C_{o}-C_{k}\right)}{m}
$$

where $\mathrm{V}$ is volume of the solution under study (0.05 l); $\mathrm{C}_{\mathrm{o}}$ and $\mathrm{C}_{\mathrm{k}}$ are starting and final concentrations of metal ions in the solution, (mg/g); $\mathrm{m}$ is the sorbent mass, g (0.5 g).
The degree of extraction of ions from the solution ( $\omega$, $\%)$ is calculated according to the formula [4]:

$$
\omega=\frac{\left(C_{o}-C_{k}\right)}{C_{o}} \cdot 100 \%
$$

Data on the value of the sorption of two factions (small fraction-1 to $2 \mathrm{~mm}$-sorbent No. 1, large fraction— 2.5 to $5.0 \mathrm{~mm}$-sorbent No. 2) are presented in Table 2.

\begin{tabular}{|c|c|c|c|c|c|c|c|}
\hline Metal & Adsorbent fraction & A, mg/g & $\omega, \%$ & Metal & Adsorbent fraction & A, mg/g & $\omega, \%$ \\
\hline \multirow{2}{*}{$\mathrm{Ni}$} & № 1 & 398 & 80 & \multirow{2}{*}{$\mathrm{Zn}$} & № 1 & 268 & 54 \\
\hline & № 2 & 494 & 98 & & № 2 & 210 & 42 \\
\hline \multirow{2}{*}{$\mathrm{Cu}$} & № 1 & 287 & 57 & \multirow{2}{*}{$\mathrm{Pb}$} & № 1 & 432 & 86 \\
\hline & № 2 & 216 & 44 & & № 2 & 469 & 92 \\
\hline \multirow{2}{*}{$\mathrm{Cd}$} & № 1 & 262 & 52 & \multirow{2}{*}{$\mathrm{Hg}$} & № 1 & 437 & 87 \\
\hline & № 2 & 248 & 50 & & № 2 & 366 & 75 \\
\hline
\end{tabular}

Table2. Adsorbing capacity of zeolite modified by sulphuric polymer

Thus, a simple method of obtaining a sorbent capable of extracting heavy metal compounds from water solutions and wastewater, based on modification of natural zeolite using available reagents, has been developed. In the future, in the staging of the enlarged laboratory tests, which were aimed at establishing optimal working modes of adsorption extraction $\mathrm{Ni}^{2+}$, $\mathrm{Zn}^{2+}, \mathrm{Cu}^{2+}$ water solutions, sorbent No. 1 was used.

\section{Results and Discussion}

As we know, the feasibility of choosing one or another method, and the technological scheme of wastewater treatment depends on the composition, concentration, mode of supply and discharge of wastewater, technological requirements for treated water, the need and the ability to regenerate and reuse water and valuable components. The most difficult is the drainage and wastewater treatment of industrial plants, as the composition and properties of wastewater depend on the specifics of water production processes [16].

In practical terms, we considered the possibility of using the newly obtained sorption materials in metal- containing wastewater treatment technologies at a number of enterprises in the Irkutsk region.

In the technical processes of an enterprise, wastewater is formed, which is characterized by different chemical composition, costs, significant fluctuations in the concentrations of heavy metals in the original solutions (before the cleaning processes), directions of disposal of purified streams. Accordingly, in the development of wastewater treatment processes at the industrial sites of enterprises, various components and hardware design of processes are made. Analysis of the effectiveness of local treatment plants for the disposal of metal-containing sewage from galvanic productions has shown that in most cases the necessary requirements for the degree of their cleaning is not achieved for various reasons, which in turn results in significant environmental-related payments for over-limit discharges.

One of the possible methods for improving the efficiency of the treatment of metal-containing wastewater and, accordingly, to achieve the requirements of regulatory discharges in urban drainage systems, is the development and implementation of the node of deep 
sorption wastewater treatment using an adsorption filter with multi-layered loading as the final stage of purification.

As a load for the adsorption filter, we propose to use a three-layer filtering material consisting of natural zeolite, modified with TEOS; a mixture of natural zeolite, thermally modified and zeolite, chemically modified with HMDS; as well as natural zeolite, modified by the sulphuric polymer produced from epichlorhydrine waste, at a ratio of 9:7.2:83.8\% respectively. The feature of such a multi-layered filter load is the developed surface of the grains, which ensures the process of filter regeneration. The threelayer filter diagram is represented in Figure 1.

First layer of filtering material 2' in the direction of the wastewater flow rate of $300 \mathrm{~m}^{3} /$ day consists of natural zeolite, modified with TEOS with the size of particles of $2-3 \mathrm{~mm}$ and the height of the layer $\mathrm{h}$ of 0.1 $\mathrm{m}$. The second layer 2"' with height of $8 \mathrm{~m}$ consists of a mixture (at a ratio of $1: 1$ ) of zeolite, thermally modified at 350 degrees for 2 hours, with the size of particles of 3 $\mathrm{mm}$ and zeolite, chemically modified with HMDS with the size of particles of 1-2 mm. Third layer 2,"' consists of natural zeolite, modified by the sulfuric polymer produced by the waste production of epichlorhydrine, with the size of particles of $1 \mathrm{~mm}$, the height the layer of $1.5 \mathrm{~m}$. The total height if the filter is $1.65 \mathrm{~m}$.

The process of deep wastewater treatment in the proposed filter is as follows: in the first layer consisting of large particles with a developed specific surface of grains, the largest particles are caught. At the same time, the total resistance of the filter does not increase, as it is determined by the lower layers consisting of smaller particles. The second, mixed layer, due to the developed fragmentation of the layer of modified zeolite forms a frame structure, in which smaller particles of the third layer are placed. The second layer prevents the siltation of the partition zone between the first and third layers. In the third layer, the smallest particles are caught.

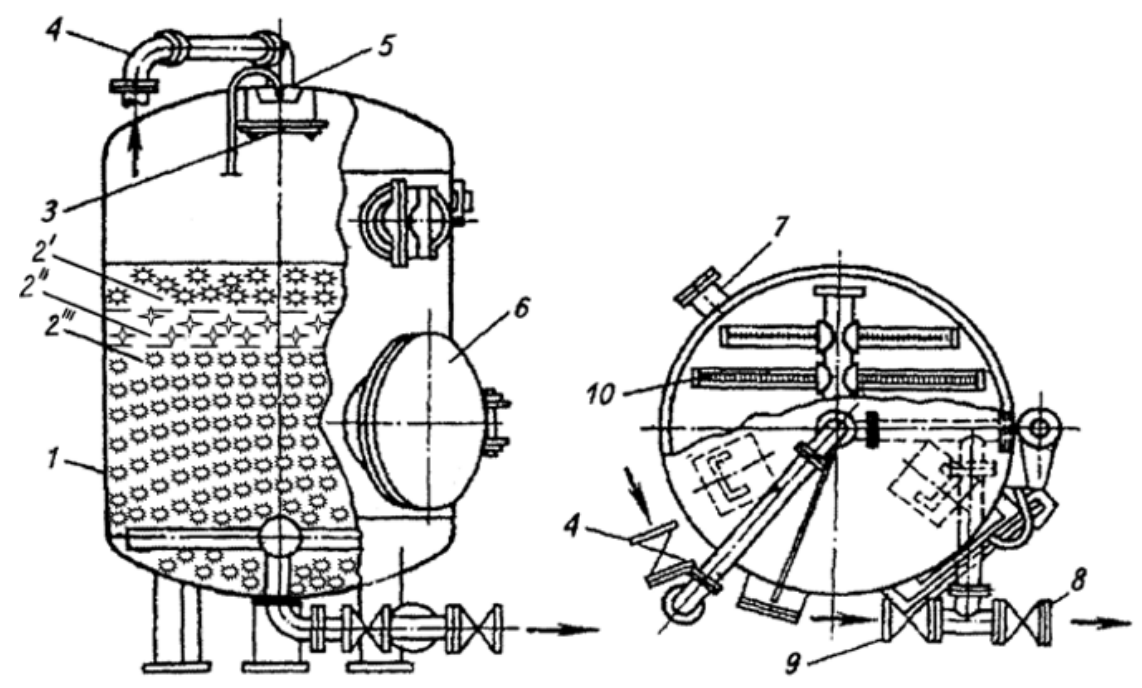

Fig. 1. The filter scheme with a three-layer loading of zeolite: 1 is housing; $2^{\prime}, 2^{\prime \prime}, 2^{2 / /}$ are zeolites of various modifications; 3 is a chipper; 4 is a pipeline that supplies wastewater for treatment; 5 is an air discharge pipe; $6 \mathrm{~s}$ a hatch; 7 is a zeolite hydraulic discharge pipeline; 8 is a clean water drainage pipeline; 9 is a hot water supply pipeline; 10 is a pipe distribution system

In the developed filter material, the degree of liquid purification from impurities is determined by the third layer and depends on the size of the particles and the height of the zeolite layer, while the load size determines the performance of the layer. The first two layers are designed to intensify the filtration of liquids through the layer: lengthening the filter cycle, increasing the dirt capacity, improving performance.

Regeneration of filter layers was done by doublewashing the layers with hot water for 30 minutes and then treating them with live steam. The filtering material is located on supporting grids that can be freely taken out of the filter case for regeneration purposes. After temperature treatment, zeolites acquire a loose structure and completely restore their sorption properties. We propose to regenerate the load once every 10 days, and replace it once every 2 months. Cleaned water after sorption filters under residual pressure enters in the amount of $20 \mathrm{~m} 3 /$ day in the reservoir of cooled water to recharge the revolving water system, and the remaining $280 \mathrm{~m} 3 /$ day is dumped in the urban sewerage, with full compliance with the requirements.

After the completion of the process of pre-cleaning and regeneration stages, the idle (washed) adsorbentzeolite-like material can be disposed of using the technologies of production of building materials taking into account the specific properties of reagents-modifiers [17-21].

\section{Conclusions}

Thus, the results of experimental and theoretical studies can be used to formulate the following conclusions:

We demonstrate that it is advisable to use natural zeolites of clinoptilolite type of the East Transbaikalia deposit modified with high-silicon compounds 
hexamethyldisilane $\left[\left(\mathrm{CH}_{3}\right)_{3} \mathrm{Si}-\right]_{2} \quad \mathrm{NH}$ (HMDS) and tetraethoxysilane $\left(\mathrm{C}_{2} \mathrm{H}_{5} \mathrm{O}\right)_{4} \mathrm{Si}$ (TEOS), sulfur polymer obtained from waste products of epichlorohydrin, as filter media in adsorption filters.

We have proven that the chemical modification of natural zeolites allows for a more orderly structure than that of natural minerals, an increased surface area and a transitional porosity, which ensures their high sorption activity in relation to copper, zinc, nickel ions and the prospect of deep wastewater treatment on the example of galvanic production.

The ecological feasibility of implementing a complex technology has been proved, which provides for the production of new sorbents based on the modification of natural zeolites (clinoptilolite type) of East Transbaikalia, their use in wastewater treatment from copper, zinc, nickel ions, providing standard indicators of the quality of purified water and the use of spent sorbents in production of building materials.

\section{References}

1. State report "On the State and Environmental Protection of the Irkutsk Region in 2018" (Megaprint LLC, Irkutsk, 2019)

2. A.D. Smirnov, Sorption water treatment (Chemistry, Moscow, 1982)

3. S. Greg, K. Sing, Adsorption, specific surface, porosity (The World, Moscow, 1984)

4. M.M. Dubinin, Adsorption and Porosity (WAHS, Moscow, 1982)

5. Dr. Inamuddin, L. Mohammad, Ion Theory and Exchange Technology (Dordrecht. Heidelberg, New York, London, 2012)

6. A. Dabrowski, Z. Hubicki, P. Podkoscielny, E. Robens, Chemosphere 56, 2 (2004)

7. H. Yamazaki, Y. Inoue, N. Kikuchi, H. Kuriha, Bull. Chem. Soc. Japan 64, 2 (1991)

8. P.A. Kotov, Deposits of Transbaikalia (Geoinformmark, Moscow, 1995)

9. A.V. Makarov, L.M. Sinegovskaya, N.A. Korchevin, Vestnik ISTU 73, 2 (2013)

10. K. Annop Krishnan, K.G. Sreejalekshmi, V. Vimexen, V. Dev Vinu, Ecotoxicology and Environmental Safety 124 (2016)

11. Yu.I. Murinov, V.N. Maistrenko, N.G. Afzaletdinova, Extraction of metals by $\mathrm{S}, \mathrm{N}$-organic compounds (Nauka, Moscow, 1993)

12. T.A. Zaporozhskih, N.V. Russava, Y.N. Silinskaya, I.V. Korabel, N.A. Korchevin, Journal of Applied Chemistry 81 (2008)

13. A.B. Redinova, IRGTU Herald 1 (2013)

14. N.S. Shagaeva, V.V. Bayandin, Y.N. Pozhidaev, Izvestia Universitetov. Applied Chemistry and Biotechnology 2, 1 (2012)

15. A. Smith, Applied AR spectroscopy (The World, Moscow, 1982)
16. S.V. Yakovlev, Y.V. Voronov, Water disposal and wastewater treatment (ASV, Moscow, 2002)

17. S.V. Mashkina. Herald of the Innovation Eurasian University 1 (2007)

18. V.N. Smirenskaya, V.I. Vereshchagin. Glass and ceramics 12 (2002)

19. L.K. Kazantseva, V.I. Vereshchagin, G.I. Ovcharenko. Building materials 4 (2001)

20. A.V. Kiseleva. Cement 8 (1989)

21. S.V. Chuppina, V.A. Jabrev, Organosilicate materials (Liteo Publishing House, St. Petersburg, 2016) 